\title{
INTEGRATED CONTEXTUAL LEARNING ENVIRONMENTS WITH SENSOR NETWORK FOR CROP CULTIVATION EDUCATION: CONCEPT AND DESIGN
}

\author{
Rin-Ichiro Taniguchi ${ }^{1}$, Daisaku Arita ${ }^{2}$, Atsushi Shimada ${ }^{1}$, Masanori Yamada ${ }^{1}$, Yoshiko Goda ${ }^{3}$, \\ Ryota Yamamoto ${ }^{4}$ and Takashi Okayasu ${ }^{1}$ \\ ${ }^{I}$ Kyushu University, Japan \\ ${ }^{2}$ The University of Nagasaki, Japan \\ ${ }^{3}$ Kumamoto University, Japan \\ ${ }^{4}$ The University of Tokyo, Japan
}

\begin{abstract}
This paper presents an outline of our project, in which we develop an observation framework for integrating lecture and contextual learning in the field of crop cultivation. Specifically, we will use multi sensing of learners' activities in classrooms, and contextual learning in fieldwork, farm planting, and farming environments. The motivation for our project is twofold: First, crop cultivation provides a powerful illustration of educational technology. It requires both explicit knowledge (from lectures) and implicit knowledge (from contextual learning outside of class). Second, from a practical viewpoint, the number of Japanese farmers is shrinking due to low income and to aging population. Thus, in order to maintain crop yields, farming skills must be transferred efficiently to novice farm workers. Herein, the major features of our framework will be described.
\end{abstract}

\section{KEYWORDS}

Crop Cultivation Education, Learning Support, Sensing System, Learning Analytics

\section{INTRODUCTION}

Recently, information and communication technology (ICT)-supported learning has become increasingly popular. This sort of instruction utilizes several types of information systems, including e-book systems, learning management systems, e-portfolios etc. It is becoming clear that these systems are quite useful, especially for textbook-based learning (i.e., understanding and memorizing facts described in textbooks). This lecture style focuses on acquiring declarative knowledge; that is, explicit knowledge. However, the lecture style is insufficient, especially for acquiring procedural knowledge in specific professional fields/subjects (Byrnes and Wasik, 1991). For example, those in the fields of crop cultivation, musical instrument playing, caregiving, etc., require practical training to acquire procedural knowledge. In professional contexts, people are required to perform well in real settings, using not only declarative knowledge, but also procedural knowledge activation. This includes skills (i.e. the "know-how" for cognitive activities) (Anderson, 1995) implicit to their fields. It takes a long time to acquire practical professional skills, implicit knowledge, or specialized cognitive processes necessary for expertise in each field (Ericsson, et al. 2018). Thus, development and implementation of learning environments which foster practical and professional skills is desirable. Our aim is to develop an ICT-based framework to accelerate or to optimize the contextual learning process. Particularly, our area of study is the field of crop cultivation. The goal is combining declarative knowledge (acquired in lectures) with procedural knowledge (mastered in a field). Procedural knowledge (required to be a professional), is related to declarative knowledge (such as concepts in a subject) (Rittle-Johnson, 2019). This point is a fundamental motive for integration of classroom learning environments with crop-cultivation learning outside of class.

The motivation for our project is twofold: First, crop cultivation provides a powerful illustration of educational technology. It requires both explicit knowledge (from lectures) the implicit knowledge (from contextual learning outside of class. We investigate the essential point of learning, and the framework we 
build can be applied to many types of subjects which require explicit and implicit knowledge. Second, from a practical viewpoint, the number of Japanese farmers is shrinking due to a decreasing birthrate and an aging population. Thus, in order to maintain crop yields, farming skills must be transferred efficiently to novice farm workers.

As illustrated in Figure 1, our project will develop an observation framework for integrating lecture and contextual learning within the field of crop cultivation. We will use multi sensing of learners' activities, farm planting, and farming environments. The goal will be realized by combining the following three major elements:

1. Formalizing a mechanism to create a knowledge map of crop cultivation activities.

2. Analyzing the learning process, with reference to both learners' knowledge maps, and the data acquired by multi sensing of their learning/training processes.

3. Instructional design-based analysis of the processes above.

In this paper, we outline a system integrating learning environments for the acquirement of knowledge (both declarative and procedural) in the fields of crop cultivation education. Finally, we suggest directions for future research.

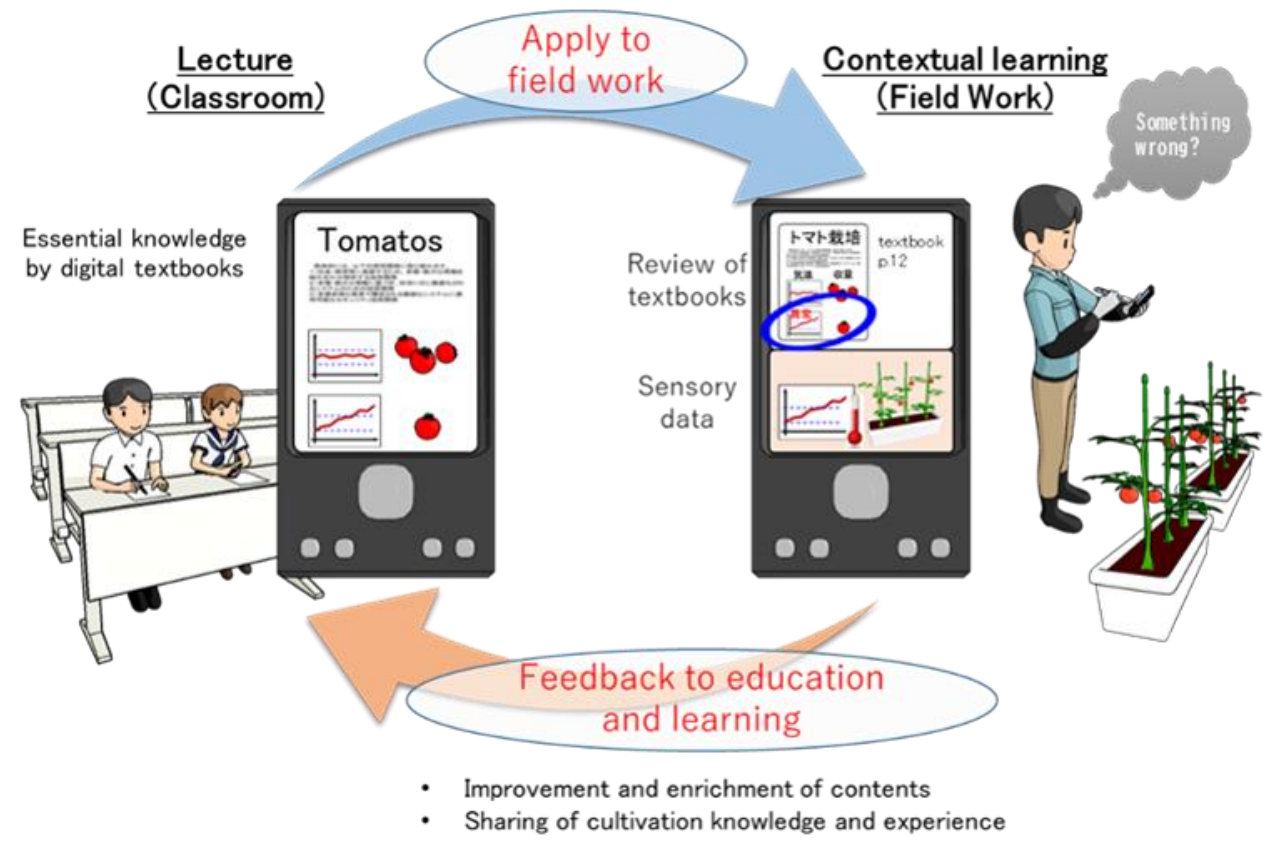

Figure 1. Project overview: seamless collaboration of lecture and contextual learning

\section{PROPOSED SYSTEM}

\subsection{System Overview}

Figure 2 shows the overview of our educational system. The Moodle system provides lecture schedule and outlines, and manages user accounts, as well as attendance information and reports submitted by students. There are three major subsystems connected to the Learning Tools Interoperability (LTI) protocol, enabling transfer of user information between systems. The subsystems consist of an e-book viewer system (BookRoll), a knowledge management system, (BR-MAP) and the sensory information visualizer (SALATA). SALATA collects sensory information (such as temperature, humidity, wind direction, and solar radiation) from the MIHARAS system. Additionally, SALATA collects user-generated contents such as photos, voices, text memos. In the following subsections, we explain the details of these subsystems. 


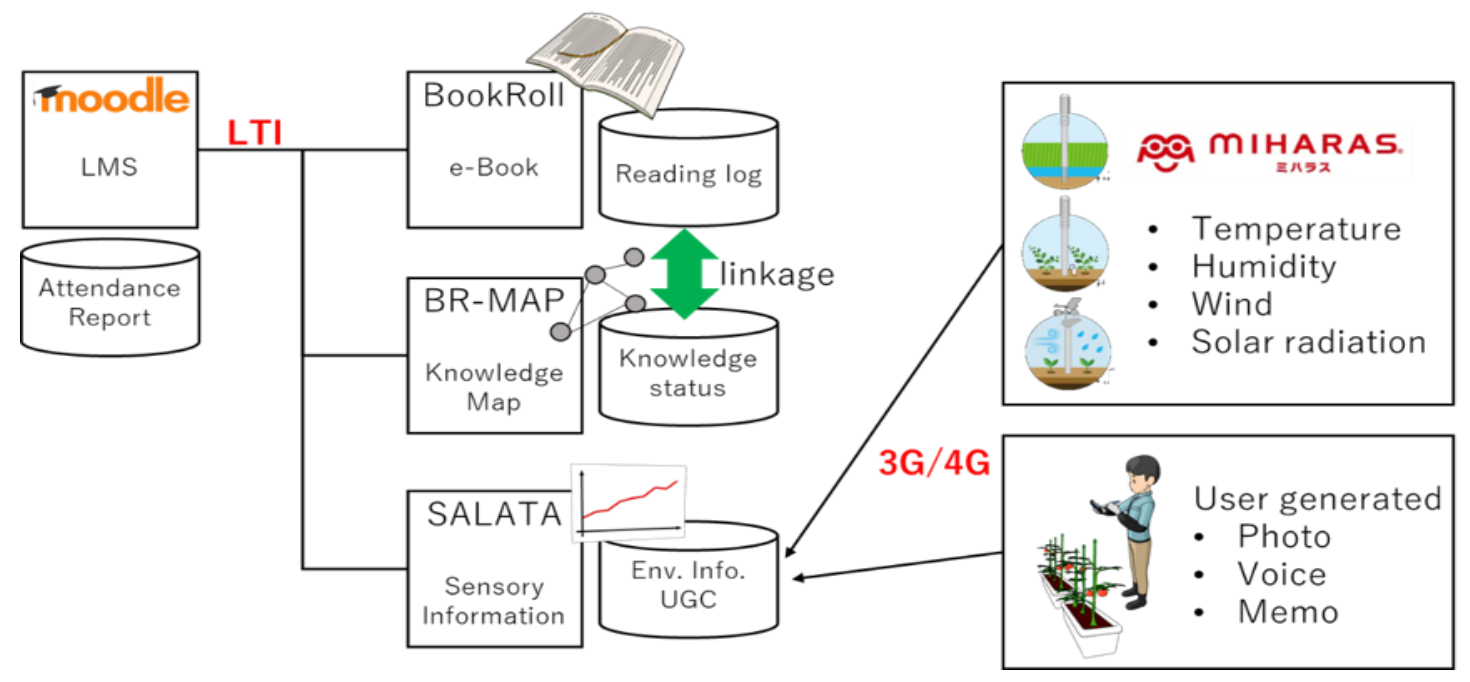

Figure 2. System overview

\subsection{Learning Management System}

The Moodle is a well-known learning management system used worldwide. In our project, we collect course attendance and daily reports from students using plugins on the Moodle (see Figure 3). A clicker is one of the most useful plugins for collecting answers on students' quizzes and questionnaires (see Figure 4). Additionally, the Moodle provides several links to the related subsystems (i.e., BookRoll, SALATA, and BR-Map).

Teachers used Moodle to manage student attendance, provide quizzes, and receive reports. Data and access logs are also collected in the Moodle database. This information is utilized for analytics of teaching and learning activities. The main role of Moodle is platform for the connection between other systems.

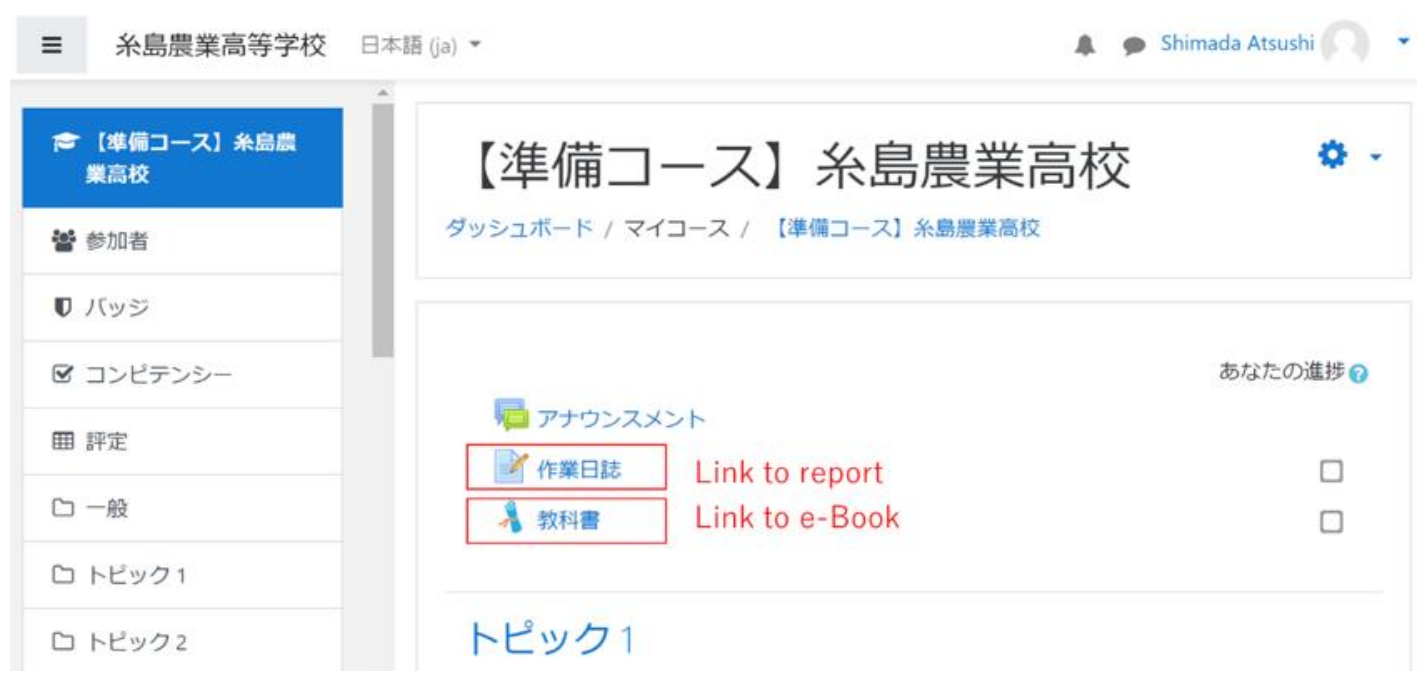

Figure 3. Example of course settings in Moodle 

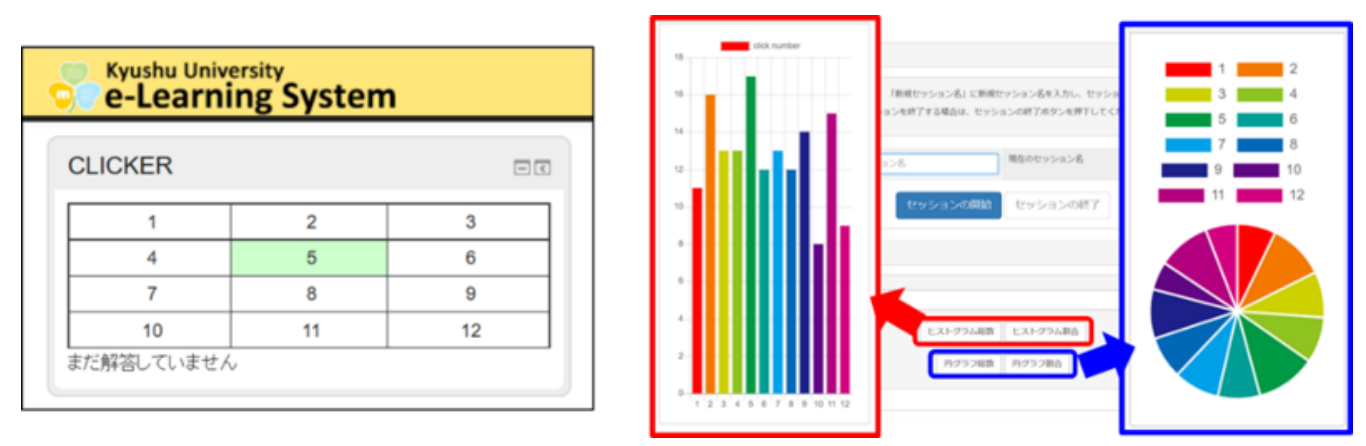

Figure 4. Clicker plugin on Moodle. Web UI for students (left), Aggregation results for teachers (right)

\section{3 e-Book Viewer}

BookRoll (Figure 5) is an e-book viewer system, developed by Kyushu University and Kyoto University (Ogata et al. 2017). Main role of the BookRoll is to promote input by reading. It provides digital textbooks to students, and collects precise reading logs (such as when a student opens material, or turns a page in in that material. Many types of operations are recorded as the logs. For example, OPEN means that the student opened the e-book file, whereas NEXT means that the student clicked the next button to move to the subsequent page. The browsing duration for each page can be easily calculated by the timestamps.

BookRoll provides useful functions, such as bookmarking, highlighting, and text memos. Students can freely and directly bookmark pages in lecture materials, highlight keywords or sentences, and write text memos reflecting their thoughts. These operations' logs are also collected into BookRoll's system database, and utilized to analyze learning activities. BookRoll is core learning support system in this project. Other learning support systems use BookRoll log, in order to collect the data that indicated learning process data. BR-Map is one of the learning support systems that use BookRoll logs.

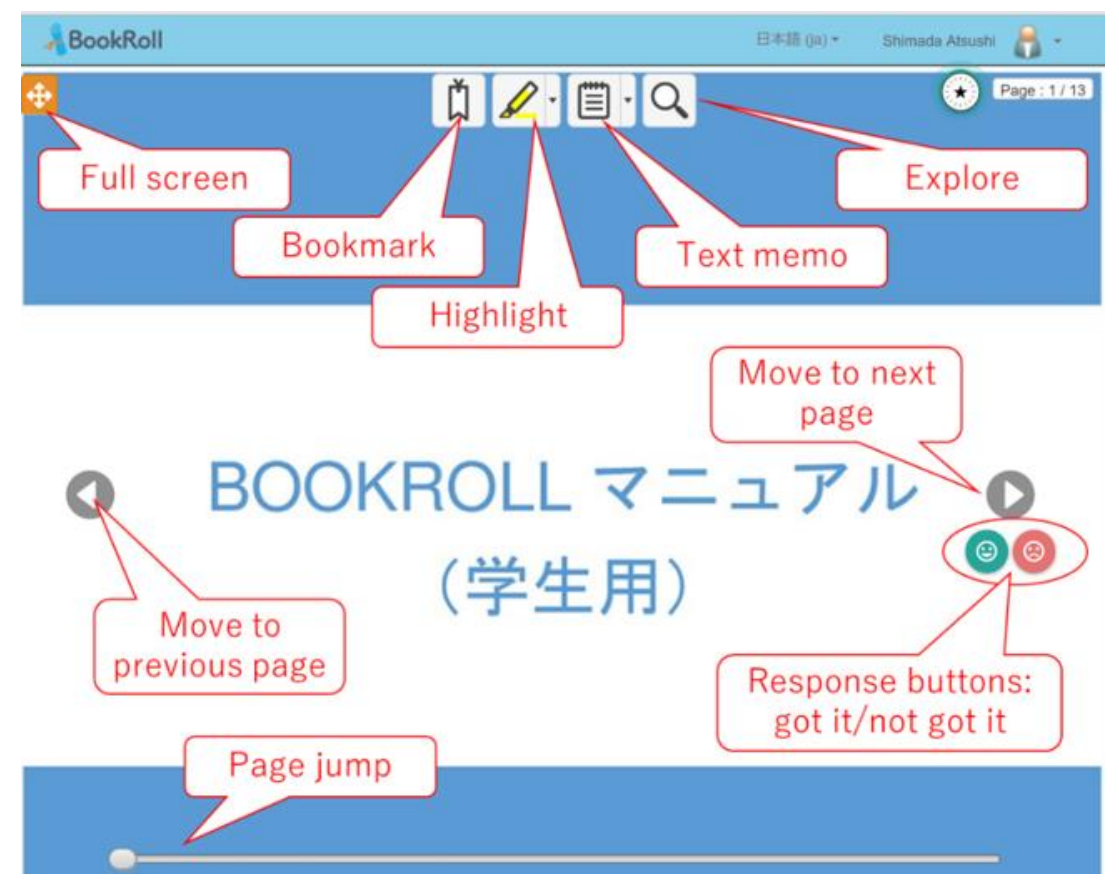

Figure 5. e-Book viewer 


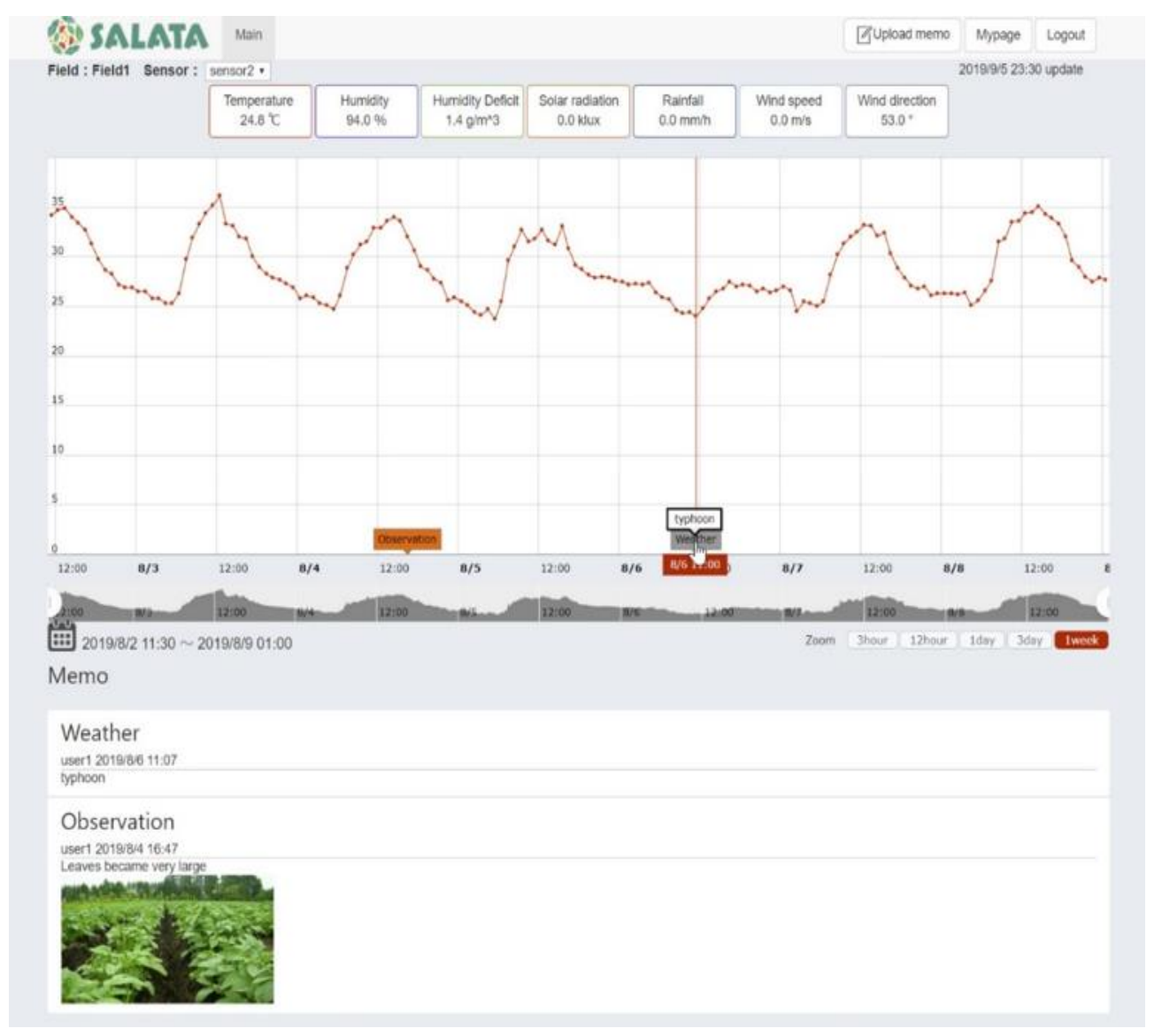

Figure 6. Temperature view in SALATA

\subsection{Sensory Information Monitoring System}

SALATA is a sensory information monitoring system for the contextual learning of crop cultivation. It was developed by Kyushu University. It has a database which stores environmental information on farm fields, to be used in contextual learning. Environmental information is measured using sensing devices. Currently, we employ MIHARAS (MIHARAS Web site), developed by Nishimu Electronics Industries Co., Ltd. It is capable of measuring: 1) temperature; 2) humidity; 3) humidity deficits; 4) solar radiation; 5) rainfall; 6) wind speed; 7) wind direction; 8) soil temperature; 9) soil moisture; and 10) soil electrical conductivity. The SALATA provides a graphical interface displaying graphs of this information. Figure 6: Temperature view in SALATA, for example, shows the temperature graph over the course of one week.

Each student brings a tablet to the farm field, examines the crops in reference to the environmental information provided by the SALATA, adding text memos and photos to the graph. These reports capture what students observe, notice and think. In Figure 6, there are two memos: the left memo's "observation" has a text "Leaves became very large" with a photo taken by a student after several fine-weather days. The right memo with a category "weather" has a text "typhoon" and is highlighted because the student taps the memo to select.

The SALATA collects not only environmental information and students' memos, but also students' operation logs. The SALATA analyzes these data sets to judge whether students understand the knowledge in the BR-Map. In this case, the BR-Map is based on the relationship between crops and the environment. For example, a student who understands that too-high humidity causes some crop diseases can write a memo regarding high- humidity-related crop diseases. In addition, the SALATA can provide hints to students in a farm field who lack understanding of the relationship between humidity and crop diseases. 


\subsection{Connecting Declarative Knowledge with Procedural Knowledge: Knowledge Map as Knowledge Connection Tool}

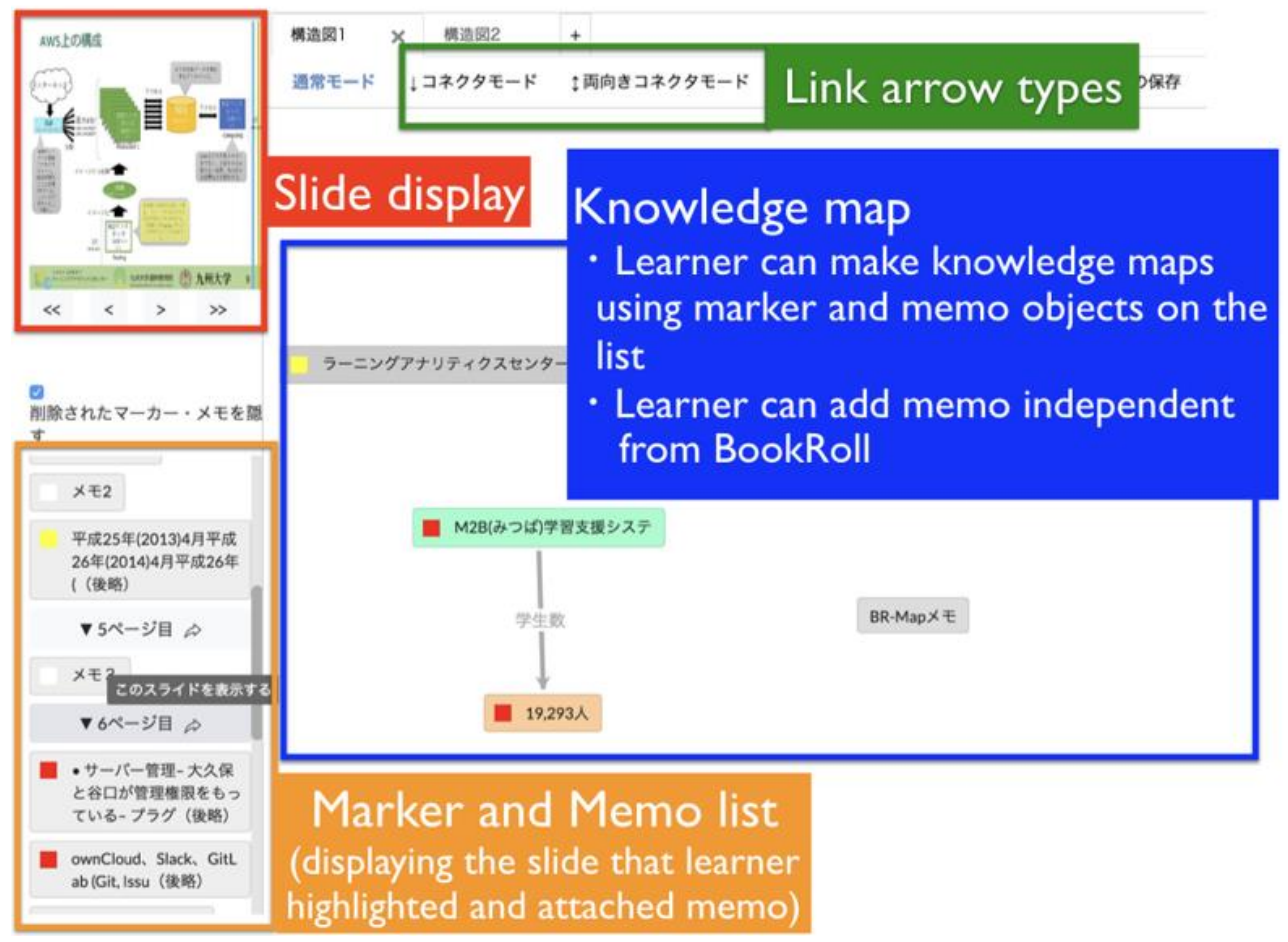

Figure 7. The interface of BR-Map (Yamada et al, 2018)

Using e-textbooks and sub-learning materials on BookRoll, students are able to absorb learning contents (such as terminology and rules of agriculture). Learners mainly gain declarative knowledge from e-textbooks. However, knowledge absorbed in class is insufficient for them to perform cultivation well in the field. Learners are required to master not only declarative knowledge (such as crop features and generally suitable weather conditions for crops) but also procedural knowledge (such as treatment in bad weather conditions, adjustment of field drainage, and real-world weather situations).

In order to effectively gain information and skills, a knowledge management platform which connects declarative knowledge with procedural knowledge is required. BR-Map (Yamada et al, 2018), a knowledge map, can connect with learning logs on BookRoll. Thus, it can serve as a knowledge management platform, allowing learners to connect declarative knowledge with procedural knowledge. Figure 7 shows the interface of BR-Map.

BR-Map uses the marker and memo logs from BookRoll. First, learners read e-textbooks on BookRoll, adding markers on parts and memos. When a learner opens BR-Map, it reads the marker and memo logs from BookRoll database, and lists them on left pane. Learners click the object on the left pane, and drag-and-drop it on the right pane's "knowledge map" area. Learners can add independent memo(s) from BookRoll to the knowledge map area. Therefore, learners connect objects using arrows, and create a knowledge map. Learners can download the knowledge map as png file.

BR-Map can serve as a knowledge management platform for the connection of declarative knowledge from lectures with procedural knowledge from fields. In order to promote the connection, BR-Map will be modified as follows: 1) read the data and action logs from SALATA; and 2) develop functions which allow learners to connect this data on knowledge map area. This process is based on Rittle-Johnson's (2019) viewpoint on the relationship between declarative and procedural knowledge. BR-Map can be effective seamless learning environment connected classroom and crop field. It allows learners to connect the knowledge learned in the class and the one learned in crop field. Learners seem to be aware of procedural knowledge in expertise process. Thus, it is expected that modified BR-Map enhances retention and interest of crop cultivation. 


\section{CONCLUSION}

In this paper, we created a design for an ICT-based educational system for crop cultivation education. This framework aims at supproting both lecture and contextual learning in the field of crop cultivation. Our proposed system will be implemented by cooperation between digital learning environments and multi sensing systems. In our future work, we plan to begin an experiment in an agricultural high school starting mid-September. The target course aims to teach cultivation of of leaf and root vegetables using classroom lectures and practical fieldwork in. Approximately forty students will participate in the experiment. We will begin collecting and analyzing learning logs from the students, and will investigate the effectiveness, usability, and usefulness of the proposed system.

\section{ACKNOWLEDGEMENT}

This work was supported by JSPS KAKENHI Grand Number JP18H04117, JP18H04125 and JP16H03080, Japan.

\section{REFERENCES}

Abiteboul, S. et al, 2000. Data on the Web: From Relations to Semistructured Data and XML. Morgan Kaufmann Publishers, San Francisco, USA.

Anderson, J.R, 1995. Cognitive Psychology and its implications, $4^{\text {th }}$ edition, W. H. Freeman and Company, New York, USA

Beck, K. and Ralph, J., 1994. Patterns Generates Architectures. Proceedings of European Conference of Object-Oriented Programming. Bologna, Italy, pp. 139-149.

Bodorik P. et al, 1991. Deciding to Correct Distributed Query Processing. In IEEE Transactions on Data and Knowledge Engineering, Vol. 4, No. 3, pp 253-265.

Byrnes, J. P and Wasik, B.A., 1991. Role of conceptual knowledge in mathematics procedural learning, Developmental Psychology, 27, pp.777-786.

Ericsson, K.A, Hoffman, R.R., Kozbelt, A, and Williams, A.M., 2018, The Cambridge Handbook of Expertise and Expert Performance, second edition, The Cambridge University Press, Cambridge, UK.

MIHARAS: https://www.nishimu-products.jp/miharas

Ogata, H., Oi,M., Mohri, K., Okubo, F., Shimada, A., Yamada, M., Wang, J., and Hirokawa, S, 2017. Learning Analytics for E-book-Based Educational Big Data in Higher Education, In H.Yasuura, C.-M.Kyung, Y.Liu, Y.-L.Lin. (Eds.) Smart Sensor at the IoT Frontier, Springer, pp.327-350

Rittle-Johnson, B., 2019. Iterative Development of Conceptual and Procedural Knowledge in Mathematics Learning and Instruction, In J.Dunlosky and K.A. Rawson (Eds.) The Cambridge Handbook of Cognition and Education, The Cambridge University Press, pp.124-147.

Yamada, M. Shimada, A., Oi, M., Taniguchi, Y., and Konomi, S., 2018. BR-MAP: Concept Map System using e-Book Logs. In 15th International Conference on Cognition and Exploratory Learning in the Digital Age (CELDA 2018), pp. 248-254. 